DOI: 10.4274/ejgg.galenos.2021.478

Eur J Geriatr Gerontol 2022;4(1):5-10

\title{
Polypharmacy Frequency: The Relationship Between Polypharmacy and Mortality in COVID-19 (+) Older Adults
}

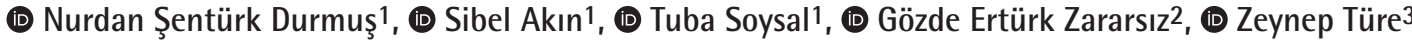 \\ ${ }^{1}$ Erciyes University Faculty of Medicine, Department of Internal Medicine, Division of Geriatrics, Kayseri, Turkey \\ 2Erciyes University Faculty of Medicine, Department of Biostatistics, Kayseri, Turkey \\ ${ }^{3}$ Erciyes University Faculty of Medicine, Department of Clinical Microbiology and Infectious, Kayseri, Turkey
}

\section{Abstract}

Objective: This study aims to determine the relationship between polypharmacy and Coronavirus disease-2019 (COVID-19) (+) related mortality.

Materials and Methods: All older adults $>60$ years old who had positive COVID-19 polymerase chain reaction tests were included in the study, designed retrospectively. Polypharmacy was defined as drug use of five or more.

Results: One hundred and ten people of $>60$ years old were included in the study. Fifty-nine (53.6\%) of the participants were male and the mean age was $70.5+8.81$. The prevalence of polypharmacy in patients diagnosed with COVID-19 infection was 31.8\% ( $n=35)$. Eighty-two (78.8\%) of participants had pneumonia. Mortality occurred in $24(21.8 \%)$ of the participants. There was no relationship between polypharmacy and mortality $(p=0.241)$. In multivariate analysis, older age was associated with mortality (odds ratio: 6.82 95\% confidence interval: 2.46-18.91, $p<0.001$ ).

Conclusion: The prevalence of polypharmacy in individuals diagnosed with COVID-19 infection was like the literature. The most significant factors in death in people with COVID-19 infection were older age. There was no relationship between polypharmacy and mortality.

Keywords: Older age, COVID, polypharmacy, mortality, coronavirus

\section{Introduction}

The pandemic of Coronavirus disease-2019 (COVID-19), which started in China in December 2019, caused the death of 1.311 .942 people, infecting about 54 million people worldwide by 15 November 2020 (1). COVID-19 infection can be asymptomaticmild upper respiratory tract infection or it can present with pneumonia and, acute respiratory distress syndrome (2-5). In many studies on COVID-19, older age and comorbidity has been associated with poor outcomes $(2,3,5-7)$. Results are worse in older adult individuals who need mechanical ventilation (3).

In Turkey, the first case was reported on 11 March 2020 - the first death was seen on 17 March 2020 (8). By 10 February 2021, total cases and deaths had reached 2.548.195 and 26.998 cases in Turkey, respectively (8).
With aging, the number of diseases increases; therefore, the number of drugs used by people increases (9). Polypharmacy is an acute geriatric syndrome (10). Polypharmacy incidence has been reported from $30 \%$ to $60 \%$ in older adults (10-12). The reason for such a difference in polypharmacy incidence is that there is no universal definition of polypharmacy (10). Some define it as drug use other than indication (12), while others define it with more drug use than a certain number of drugs $(10,13)$. Polypharmacy has been associated with many clinical conditions such as falls, mortality, adverse drug events, impaired cognition, and frailty $(10,11,14)$. Until now, many factors related to mortality have been revealed in patients with a diagnosis of COVID-19, but there are a limited number of studies evaluating them in terms of geriatric syndromes $(3,6,15)$. In the studies performed, mortality with frailty was evaluated, and unlike expectedly, no relation with mortality in frail patients was

Address for Correspondence: Sibel Akın, Erciyes University Faculty of Medicine, Department of Internal Medicine, Division of Geriatrics, Kayseri, Turkey

Phone: +90 3522076666 E-mail: sibelyanmaz@gmail.com ORCID: orcid.org/0000-0002-6139-7254

Received: 08.01.2021 Accepted: 03.03.2021

Cite this article as: Şentürk Durmuş N, Akın S, Soysal T, Ertürk Zararsız G, Türe Z. Polypharmacy Frequency: The Relationship Between Polypharmacy and Mortality in COVID-19 (+) Older Adults. Eur J Geriatr Gerontol 2022;4(1):5-10

๑Copyright 2022 by the Academic Geriatrics Society / European Journal of Geriatrics and Gerontology published by Galenos Publishing House. 
shown $(6,15)$. There are few studies of the relationship between polypharmacy and COVID-19 related mortality, and their results are conflicting $(3,6)$.

This study aimed to clarify the relationship between COVID-19 and polypharmacy because the research results published so far are contradictory. This study aims to determine the prevalence of polypharmacy in patients diagnosed with COVID-19 (+), to investigate whether the presence of polypharmacy in patients with COVID-19 (+) has an impact on mortality, and to identify other causes of mortality in people diagnosed with COVID-19 $(+)$.

\section{Materials and Methods}

All older adults $>60$ years old who had a positive COVID-19 polymerase chain reaction (PCR) test at Erciyes University Medical School Hospital were included in the study. Erciyes University Medical School Hospital was the reference hospital for the pandemic. This research had been designed retrospectively. For the retrospective design, we did not evaluate the comprehensive geriatric assessment and frailty status of patients.

The files of the participants included in the study were scanned retrospectively. Their socio-demographic characteristics (age, gender), comorbidities [e.g., chronic obstructive pulmonary disease, cancer, hypertension (HT), coronary artery disease, chronic kidney disease, and/or diabetes mellitus (DM)], the number of drugs, the types of drugs, the presence of pneumonia, the history of admission on intensive care unit (ICU), the history of mechanical ventilation and the presence of mortality were recorded.

COVID-19 was detected by real-time reverse transcriptase-PCR assay of samples collected by using nasopharyngeal swabs. Computed tomography (CT) was performed on all patients without contraindications (claustrophobia, etc.), who resulted in COVID-19 PCR positive. A specialist radiologist evaluated CT. Patients with infiltration on CT were considered to have COVID-19 pneumonia.

In this study, five or more drug use was defined as polypharmacy (10). When the patients admitted to the hospital, those who used five or more medications regularly for the last year were accepted as "polypharmacy". The drugs were recorded through the patients' reports during hospitalization and controlled from the medulla system (in Turkey). The drugs used by the patients were categorized as antihypertensive, antiaggregant, anticoagulant, antidepressant, antidiabetic (AD) drugs, inhaler drugs, antilipidemic drugs, immunosuppressant drugs, and proton pump inhibitors (PPIs).

This research was approved by the Erciyes University Ethics Committee (date: 10.06.2020, number: 2020/285). Consent was obtained from the participants or their relatives.

\section{Statistics}

Histogram, q-q plots are examined, and the Shapiro-Wilk's test was applied to assess the data normality. Levene test was used to test variance homogeneity. To compare the differences between groups, the Pearson chi-square test or Fisher's Exact test were applied for categorical variables to compare the differences between groups. Mann-Whitney $U$ tests were applied for continuous variables. Binary logistic regression analysis models were built to investigate the effect of variables in estimating mortality in geriatric patients. Crude, age, and gender-adjusted, and multiple models were fitted separately. Significant variables at $p<0.25$ were included in numerous models, and backward elimination was performed to identify independent risk factors. Wald statistic was used as a model selection criterion. HosmerLemeshow tests were used for the goodness of fit test. Odds ratios were calculated with 95\% confidence intervals. All analyses were performed using TURCOSA (Turcosa Analytics Ltd. Co., www.turcosa.com.tr) statistical software. P-values less than $5 \%$ were considered as statistically significant.

\section{Results}

One hundred ten people of $>60$ years old were included in this research. Fifty-nine (53.6\%) of the participants were male and the mean age was 70.5 (64.0-78.2, standard deviation 8.81). Ninety-five $(86.4 \%)$ of the participants had comorbidities. The most common comorbidity was HT with $61.8 \%(n=68)$ patients, the second was DM with $28.2 \%(n=31)$ patients. Polypharmacy was recorded in $31.8 \%(n=35)$. The most widely used drugs were diuretics (hydroxychlorothiazide, spironolactone) $(n=41,37.3 \%)$, beta-blockers ( $n=34,30.9 \%)$, acetyl-salicylic acid (ASA) $(n=32$, $29.1 \%)$, angiotensin receptor blockers (ARB) $(n=31,28.2 \%)$, calcium channel blockers $(n=26,23.6 \%)$, angiotensin-converting enzyme inhibitors (ACE-I) $(n=24,21.8 \%)$ and metformin $(n=21,19.1 \%)$. While a total of $78.8 \%(n=82)$ had COVID-19 pneumonia. Ten (9.1\%) of 110 participants had a history of admission in ICU, and five (4.5\%) had mechanical ventilation. Mortality occurred in $21.8 \%(n=24)$ of the participants. Table 1 shows the demographic and clinical characteristics of the participants according to mortality. The participants who had mortality were older (69 vs. 79.5, $p<0.001$ ). Moreover, the mortality rate was higher in hospitalized individuals (69.8\% vs. $100 \%, p=0.002$ ). Table 2 shows the relationship between drug groups and mortality. There was no relationship between any drug group and mortality. Thirteen (22.0\%) of the patients with mortality were male and $21.6 \%(n=11)$ were female $(p=0.570)$. Twelve (13.8\%) of those with mortality were between the ages of $60-79$ and $52.2 \%(n=12)$ were over 80 years old $(p<0.001)$. While no mortality occurred in patients who were followed at home, mortality was observed in all hospitalized and followed up ( $p=0.002)$. Admission in ICU and history of mechanical ventilation were not associated with mortality $(p=0.08$ and 
0.227, respectively), but the number of patients was very low for these parameters.

The Hosmer-Lemeshow test was applied for each final models resulted in $X^{2}=0.371 p=0.831$ for mortality. These results revealed the built multiple binary logistic regression model's appropriateness in predicting the clinical outcomes in geriatric patients. Table 3 shows the univariate, adjusted, and multiple logistic regression analysis results identifying the risk factors of mortality. In univariate analysis, we found that people with intubation history increased the mortality risk 48.6 times (odds ratio: 48.60 95\% confidence interval 13.35-176.94, $\mathrm{p}<0.001$ ). History of intubation was not included in the multivariate analysis since it would suppress all other multivariate analysis parameters. Gender, polypharmacy, and the presence of COVID pneumonia parameters do not affect mortality in univariate analysis. We found that age was the only parameter affecting mortality in univariate analysis. When an adjusted model was established considering the effects of age and gender, that the variables of polypharmacy and the presence of COVID pneumonia do not affect mortality. In our study, the only factor that affects mortality was age. Patients aged 80 and over had a mortality rate of 6.82 times higher than patients aged 60-79 $(p<0.001)$. The same situation was similar in the multiple models.

\section{Discussion}

In the present study, the prevalence of polypharmacy in patients diagnosed with COVID-19 infection was 31.8\%. Mortality occurred in $21.8 \%$ of the participants. There was no relationship between polypharmacy and mortality. The most important factor associated with mortality was older age.

Until now, quite a few studies have examined the relationship between polypharmacy and COVID-19. In one of them, De Smet et al. (6) reported a higher prevalence of polypharmacy than ours $(64 \%$ vs. $31.8 \%)$, but the number of patients in this study was less than our study. Until now, there were very few publications on polypharmacy and COVID-19 related mortality. While no relationship was found between mortality and polypharmacy in one of these studies (6), another study found polypharmacy to increase the mortality risk (3). Polypharmacy has been shown to increase mortality in older adults in many meta-analyses $(11,12)$. However, surprisingly, this study did not show an association between polypharmacy and mortality $(41.7 \%$ vs. $29.1 \%, p=0.241)$. Therefore, some things that affect outcomes in COVID-19 infection may be thought to be different from prognostic factors (age, sex, polypharmacy, and comorbidities) described in other cases. More research is needed to clarify the relationship between polypharmacy and COVID-19.

\begin{tabular}{|c|c|c|c|c|}
\hline Variables & $\begin{array}{l}\text { Total } n(\%) \\
n=110\end{array}$ & $\begin{array}{l}\text { Survivors } n(\%) \\
n=86(78.2)\end{array}$ & $\begin{array}{l}\text { Non-survivors } n(\%) \\
n=24(21.8)\end{array}$ & $\mathbf{p}$ \\
\hline Age & $70.50(64.0-78.2)$ & $69.00(63.75-76.00)$ & 79.50 (71.00-87.00) & $<0.001$ \\
\hline $\begin{array}{l}\text { Age } \\
60-79 \\
\geq 80 \\
\end{array}$ & $\begin{array}{l}87(79.1) \\
23(20.9)\end{array}$ & $\begin{array}{l}75(86.2) \\
11(47.8)\end{array}$ & $\begin{array}{l}12(13.8) \\
12(52.2)\end{array}$ & $<0.001$ \\
\hline $\begin{array}{l}\text { Gender } \\
\text { Male } \\
\text { Female }\end{array}$ & $\begin{array}{l}59(53.6) \\
51(46.4)\end{array}$ & $\begin{array}{l}46(78.0) \\
40(78.4)\end{array}$ & $\begin{array}{l}13(22.0) \\
11(21.6)\end{array}$ & 0.953 \\
\hline $\begin{array}{l}\text { Comorbidity } \\
\text { HT } \\
\text { DM } \\
\text { CAD } \\
\text { COPD } \\
\text { CKD } \\
\text { Carcinoma }\end{array}$ & $\begin{array}{l}68(61.8) \\
31(28.2) \\
28(25.5) \\
17(15.5) \\
4(3.6) \\
5(4.5)\end{array}$ & $\begin{array}{l}52(60.50) \\
24(27.90) \\
21(24.40) \\
14(16.30) \\
2(2.30) \\
4(4.7)\end{array}$ & $\begin{array}{l}16(66.70) \\
7(29.20) \\
7(29.20) \\
3(12.50) \\
2(8.30) \\
1(4.2)\end{array}$ & $\begin{array}{l}0.580 \\
0.903 \\
0.637 \\
0.651 \\
0.164\end{array}$ \\
\hline Number of comorbidity & $2.0(1.0-3.0)$ & $2.0(1.0-3.0)$ & $2.0(1.0-3.0)$ & 0.572 \\
\hline Number of drugs & $3.00(1.00-5.20)$ & $3.00(1.00-5.00)$ & $3.50(2.00-6.00)$ & 0.450 \\
\hline Polypharmacy & $35(31.80)$ & $25(29.10)$ & $10(41.70)$ & 0.241 \\
\hline Presence of COVID pneumonia & $82(78.80)$ & 67 (77.90) & $15(62.50)$ & 0.126 \\
\hline $\begin{array}{l}\text { Follow-up status } \\
\text { Home } \\
\text { Hospital }\end{array}$ & $\begin{array}{l}26(23.60) \\
84(76.40) \\
\end{array}$ & $\begin{array}{l}26(30.20) \\
60(69.80) \\
\end{array}$ & $\begin{array}{l}0(0.0) \\
24(100)\end{array}$ & 0.002 \\
\hline Admission on ICU & $34(30.90)$ & $10(11.60)$ & $24(100)$ & $<0.001$ \\
\hline Mechanical ventilation & $5(4.50)$ & $5(5.80)$ & $18(75.00)$ & $<0.001$ \\
\hline
\end{tabular}


There were many studies in the literature that have examined various drug groups and the relationship of COVID-19. In some of these researches, the use of metformin $(16,17)$, DPP4-I (16), ACE-I (18-20), ARB (18-20), statins $(20,21)$ and chronic anticoagulants $(22,23)$ was protective against COVID-19-related mortality. However, results in other studies were in the opposite direction. Kocayigit et al. (24), found no association between mortality and type of antihypertensive agents' use. In the study of Cheng et al. (25), no effect of metformin use on mortality was found. In research investigating the relationship between many drug groups and mortality in Iran (26), only statin group drugs decreased mortality. In contrast, non-steroidal antiinflammatory drugs, ACE-I, and ARB use did not show any effect on death. In another study on diabetic COVID-19 patients (27), the use of $A D$ agents (insulin, metformin, sulfonylurea, and DPP-4 inhibitors) did not have a protective effect on mortality. The factors that were effective in drugs to prevent mortality in those researches improve the immune response, reduce the inflammatory response, block renin-angiotensin-aldosterone system, and prevent the formation of thrombosis $(17,19,21,22)$. Our study examined the relationship between nine different drug groups (antihypertensive, antiaggregant, anticoagulant, immunosuppressant, inhaler, antidepressant, antilipidemic and AD drugs, and PPI) and mortality, and we found no relationship
(Table 2). Randomized controlled studies are needed to understand precisely what the effects of drugs on COVID-19 related mortality.

When the patients with mortality in COVID-19 patients were examined in the literature, it was seen that 20-80\% of them were over 60 years old $(2,4,28,29)$. In some research in Turkey $(3,5)$, were like our research for over 60 years older patients (23.1\% vs. $21.8 \%, 21.2 \%$ vs. $21.8 \%$ ). When we divide it into groups by age, the mortality rates are similar to the literature and in Turkey $(3,30,31)$. In our research, the mortality rate between the ages of $60-79$ was $13.8 \%$, and over 80 years old, was $52.2 \%$, respectively. We found that the mortality risk increased approximately seven times in individuals aged 80 and over. As in our research, many studies have reported that older age was a risk factor in COVID-19 related deaths $(3,6,7,15,24,28,29)$. Why is COVID-19 infection more mortal in older adults? Immunosenescence, or changes in the age-related immune system, primarily affects the adaptive immune system (32). Accordingly, intracellular pathogens are more frequent and/or severe infections (33). A decrease in T-cell and B-cell functions in relation to older age makes it challenging to limit viral replication (32). Both older age and increasing type 2 cytokine production impairs cellmediated immune responses to infectious challenge (32). Also,

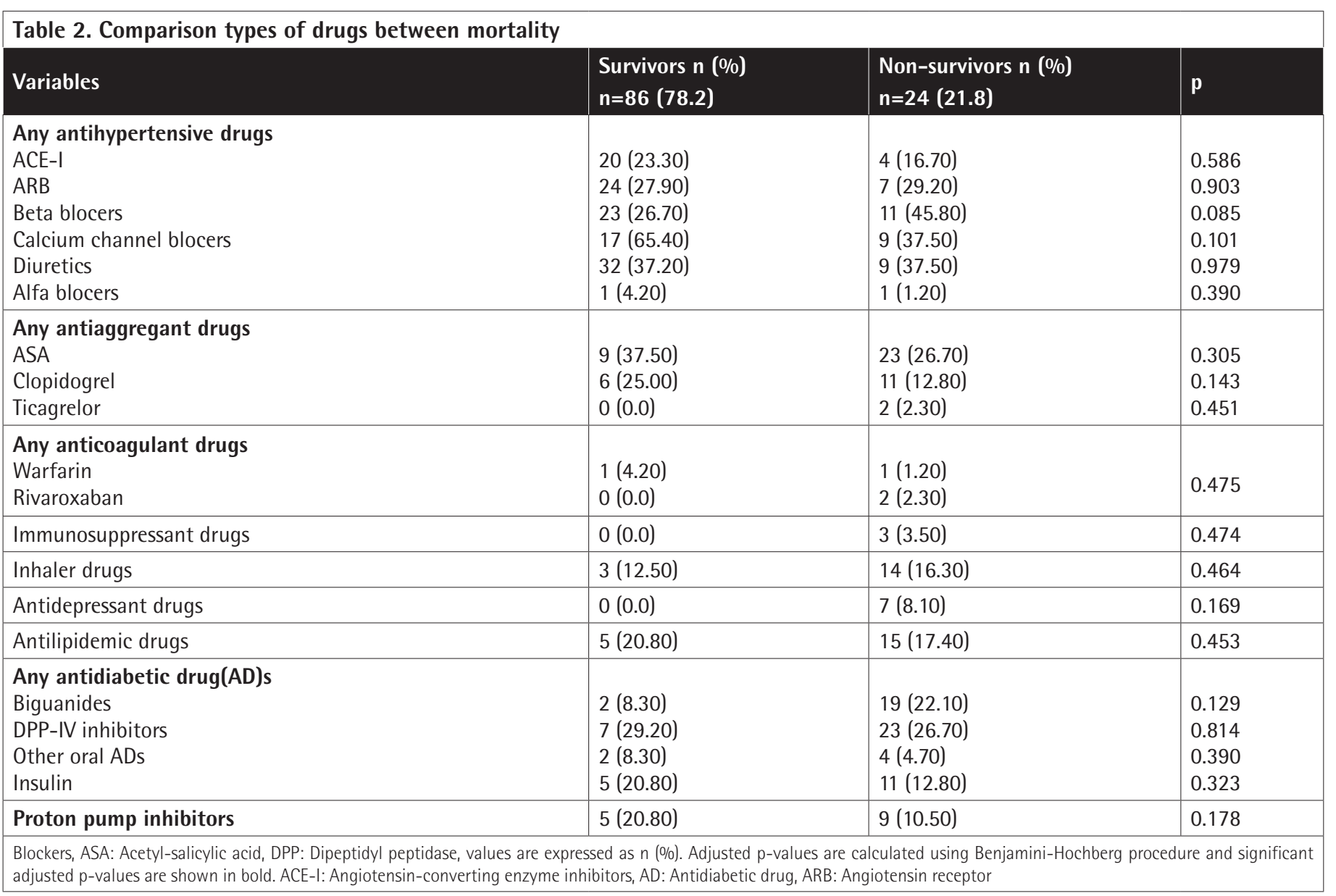




\begin{tabular}{|c|c|c|c|c|c|c|}
\hline & \multicolumn{2}{|l|}{ Crude model } & \multicolumn{2}{|l|}{ Adjusted model } & \multicolumn{2}{|c|}{ Multivariate model } \\
\hline & OR $(95 \% \mathrm{Cl})$ & $\mathbf{p}$ & OR $(95 \% \mathrm{Cl})$ & $\mathbf{p}$ & OR $(95 \% \mathrm{Cl})$ & $\mathbf{p}$ \\
\hline $\begin{array}{l}\text { Gender } \\
\text { Male } \\
\text { Female } \\
\end{array}$ & $\begin{array}{l}0.97(0.39-2.41) \\
1.00\end{array}$ & $\begin{array}{l}0.953 \\
- \\
\end{array}$ & - & - & - & - \\
\hline $\begin{array}{l}\text { Polypharmacy } \\
\text { (>5 drugs) }\end{array}$ & $1.74(0.68-4.42)$ & 0.244 & $1.78(0.65-4.93)$ & 0.264 & - & - \\
\hline Presence of COVID pneumonia & $0.47(0.18-1.25)$ & 0.130 & $0.48(0.16-1.37)$ & 0.169 & - & - \\
\hline
\end{tabular}

susceptibility to thrombosis and thromboembolism increases with older age (32,34-36). Systemic inflammation is a condition that enhances procoagulant effects $(34,35)$. Many studies published to date have found abnormalities in coagulationrelated values in laboratory tests, and these abnormalities were associated with mortality in COVID-19 patients $(2,4,37)$. For these reasons, COVID-19 infection is more severe and mortal in older adults.

\section{Study Limitations}

There are some limitations to this study. The most important limitation was single-centered and of small sample size of the present study. Also, people with negative tests but radiologically with COVID-19 pneumonia were not included in this study. Therefore, the findings in this study, unfortunately, do not reflect all individuals with COVID-19 pneumonia. The government determines hospitalization and treatment algorithms for people diagnosed with COVID-19. So, there must be some selective bias. One of the limitations was that the presence of drug-drug interaction had not been studied. There was no information about the laboratory parameters and treatment modalities of the participants. Therefore, the effects of the treatments received by individuals on mortality have not been studied. Further studies are still needed.

\section{Conclusion}

In summary, the prevalence of polypharmacy in individuals diagnosed with COVID-19 infection is like the literature. The most significant effect on mortality in people with COVID-19 infection is older age. Further studies with more participants are needed to clarify the relationship between COVID-19 infection and polypharmacy.

\section{Ethics}

Ethics Committee Approval: This study is approved by the Erciyes University Ethics Committee (date: 10.06.2020, number: 2020/285).
Informed Consent: Consent was obtained from the participants or their relatives.

Peer-review: Externally and internally peer-reviewed.

\section{Authorship Contributions}

Concept: N.Ş.D., S.A., Design: N.Ş.D., S.A., Data Collection or Processing: N.S..D., S.A., T.S., Z.T., Analysis or Interpretation: N.Ş.D., G.E.Z., S.A., Literature Search: N.Ş.D., S.A., Writing: N.Ş.D., S.A.

Conflict of Interest: No conflict of interest was declared by the authors.

Financial Disclosure: The authors declared that this study received no financial support.

\section{References}

1. https://coronavirus.jhu.edu/map.html.

2. Zhou F, Yu T, Du R, Fan G, Liu Y, Liu Z, Xiang J, Wang Y, Song B, Gu X, Guan L, Wei Y, Li H, Wu X, Xu J, Tu S, Zhang Y, Chen H, Cao B. Clinical course and risk factors for mortality of adult inpatients with COVID-19 in Wuhan, China: a retrospective cohort study. Lancet 2020;395:1054-1062.

3. Esme M, Koca M, Dikmeer A, Balci C, Ata N, Dogu BB, Cankurtaran M, Yilmaz M, Celik O, Unal GG, Ulgu MM, Birinci S. Older Adults With Coronavirus Disease 2019: A Nationwide Study in Turkey. J Gerontol A Biol Sci Med Sci 2021;76:e68-e75.

4. Chen N, Zhou M, Dong X, Qu J, Gong F, Han Y, Qiu Y, Wang J, Liu Y, Wei Y, Xia $J$, Y U T, Zhang X, Zhang L. Epidemiological and clinical characteristics of 99 cases of 2019 novel coronavirus pneumonia in Wuhan, China: a descriptive study. Lancet 2020;395:507-513.

5. Medetalibeyoglu A, Senkal N, Kose M, Catma Y, Bilge Caparali E, Erelel M, Oral Oncul M, Bahat G, Tukek T. Older Adults Hospitalized with Covid-19: Clinical Characteristics and Early Outcomes from a Single Center in Istanbul, Turkey. J Nutr Health Aging 2020;24:928-937.

6. De Smet $R$, Mellaerts $B$, Vandewinckele $H$, Lybeert $P$, Frans $E$, Ombelet $S$, Lemahieu W, Symons R, Ho E, Frans J, Smismans A, Laurent MR. Frailty and Mortality in Hospitalized Older Adults With COVID-19: Retrospective Observational Study. J Am Med Dir Assoc 2020;21:928-932.e1.

7. Li T, Lu L, Zhang W, Tao Y, Wang L, Bao J, Liu B, Duan J. Clinical characteristics of 312 hospitalized older patients with COVID-19 in Wuhan, China. Arch Gerontol Geriatr 2020;91:104185.

8. Ministry of Health - Republic of Turkey https://covid19.saglik.gov.tr/. 
9. Franchi $C$, Tettamanti $M$, Pasina $L$, Djignefa $C D$, Fortino I, Bortolotti $A$, Merlino L, Nobili A. Changes in drug prescribing to Italian communitydwelling elderly people: the EPIFARM-Elderly Project 2000-2010. Eur J Clin Pharmacol 2014;70:437-443.

10. Masnoon N, Shakib S, Kalisch-Ellett L, Caughey GE. What is polypharmacy? A systematic review of definitions. BMC Geriatr 2017;17:230.

11. Wastesson JW, Morin L, Tan ECK, Johnell K. An update on the clinical consequences of polypharmacy in older adults: a narrative review. Expert Opin Drug Saf 2018;17:1185-1196.

12. Fulton MM, Allen ER. Polypharmacy in the elderly: a literature review. J Am Acad Nurse Pract 2005;17:123-132.

13. Kaufman DW, Kelly JP, Rosenberg L, Anderson TE, Mitchell AA. Recent patterns of medication use in the ambulatory adult population of the United States: the Slone survey. JAMA 2002;287:337-344.

14. Gutiérrez-Valencia $M$, Izquierdo $M$, Cesari $M$, Casas-Herrero Á, Inzitari $M$, Martinez-Velilla $\mathrm{N}$. The relationship between frailty and polypharmacy in older people: A systematic review. Br J Clin Pharmacol 2018;84:1432-1444.

15. Knopp P, Miles A, Webb TE, Mcloughlin BC, Mannan I, Raja N, Wan B, Davis D. Presenting features of COVID-19 in older people: relationships with frailty, inflammation and mortality. Eur Geriatr Med 2020;11:1089-1094.

16. Singh AK, Khunti K. Assessment of risk, severity, mortality, glycemic control and antidiabetic agents in patients with diabetes and COVID-19: A narrative review. Diabetes Res Clin Pract 2020;165:108266.

17. Luo P, Qiu L, Liu Y, Liu XL, Zheng JL, Xue HY, Liu WH, Liu D, Li J. Metformin Treatment Was Associated with Decreased Mortality in COVID-19 Patients with Diabetes in a Retrospective Analysis. Am J Trop Med Hyg 2020;103:6972.

18. Rodilla E, Saura A, Jiménez I, Mendizábal A, Pineda-Cantero A, LorenzoHernández $E$, Fidalgo-Montero MDP, López-Cuervo JF, Gil-Sánchez $R$,

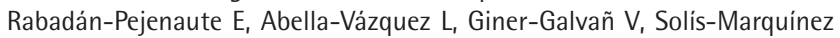
MN, Boixeda R, Peña-Fernández A, Carrasco-Sánchez FJ, González-Moraleja J, Torres-Peña JD, Guisado-Espartero ME, Escobar-Sevilla J, Guzmán-García M, Martín-Escalante MD, Martínez-González ÁL, Casas-Rojo JM, GómezHuelgas R. Association of Hypertension with All-Cause Mortality among Hospitalized Patients with COVID-19. J Clin Med 2020;9:3136.

19. Chen R, Yang J, Gao X, Ding X, Yang $Y$, Shen $Y$, He C, Xiang H, Ke J, Yuan F, Cheng R, Lv H, Li P, Zhang L, Liu C, Tan H, Huang L. Influence of blood pressure control and application of renin-angiotensin-aldosterone system inhibitors on the outcomes in COVID-19 patients with hypertension. J Clin Hypertens (Greenwich) 2020;22:1974-1983.

20. De Spiegeleer A, Bronselaer A, Teo JT, Byttebier G, De Tré G, Belmans L, Dobson R, Wynendaele E, Van De Wiele C, Vandaele F, Van Dijck D, Bean D, Fedson D, De Spiegeleer B. The Effects of ARBs, ACEis, and Statins on Clinical Outcomes of COVID-19 Infection Among Nursing Home Residents. J Am Med Dir Assoc 2020;21:909-914.e2.

21. Rodriguez-Nava G, Trelles-Garcia DP, Yanez-Bello MA, Chung CW, TrellesGarcia VP, Friedman HJ. Atorvastatin associated with decreased hazard for death in COVID-19 patients admitted to an ICU: a retrospective cohort study. Crit Care 2020;24:429.

22. Inama G, Dodi C, Provini M, Bossoni E, Inama L, Balzarini L, Mancini C, Ramponi S, Marvisi M. Coronavirus disease 2019 infection in patients with recent cardiac surgery: does chronic anticoagulant therapy have a protective effect? J Cardiovasc Med (Hagerstown) 2020;21:765-771.

23. Tremblay $D$, van Gerwen $M$, Alsen $M$, Thibaud $S$, Kessler A, Venugopal S, Makki I, Qin Q, Dharmapuri S, Jun T, Bhalla S, Berwick S, Feld J, Mascarenhas J, Troy
K, Cromwell C, Dunn A, Oh WK, Naymagon L. Impact of anticoagulation prior to COVID-19 infection: a propensity score-matched cohort study. Blood 2020;136:144-147.

24. Kocayigit I, Kocayigit $H$, Yaylaci $S$, Can $Y$, Erdem AF, Karabay 0. Impact of antihypertensive agents on clinical course and in-hospital mortality: analysis of 169 hypertensive patients hospitalized for COVID-19. Rev Assoc Med Bras (1992) 2020;66(Suppl 2):71-76.

25. Cheng X, Liu YM, Li H, Zhang X, Lei F, Qin JJ, Chen Z, Deng KQ, Lin L, Chen MM, Song $X$, Xia M, Huang $X$, Liu W, Cai J, Zhang XJ, Zhou F, Zhang P, Wang Y, Ma X, Xu Q, Yang J, Ye P, Mao W, Huang X, Xia J, Zhang BH, Guo J, Zhu L, Lu Z, Yuan Y, Wei X, She ZG, Ji YX, Li H. Metformin Is Associated with Higher Incidence of Acidosis, but Not Mortality, in Individuals with COVID-19 and Pre-existing Type 2 Diabetes. Cell Metab 2020;32:537-547.e3.

26. Alamdari NM, Afaghi S, Rahimi FS, Tarki FE, Tavana S, Zali A, Fathi M, Besharat S, Bagheri L, Pourmotahari F, Irvani SSN, Dabbagh A, Mousavi SA. Mortality Risk Factors among Hospitalized COVID-19 Patients in a Major Referral Center in Iran. Tohoku J Exp Med 2020;252:73-84.

27. Kim MK, Jeon JH, Kim SW, Moon JS, Cho NH, Han E, You JH, Lee JY, Hyun M, Park JS, Kwon YS, Choi YK, Kwon KT, Lee SY, Jeon EJ, Kim JW, Hong HL, Kwon HH, Jung CY, Lee YY, Ha E, Chung SM, Hur J, Ahn JH, Kim NY, Kim SW, Chang HH, Lee YH, Lee J, Park KG, Kim HA, Lee JH. The Clinical Characteristics and Outcomes of Patients with Moderate-to-Severe Coronavirus Disease 2019 Infection and Diabetes in Daegu, South Korea. Diabetes Metab J 2020;44:602-613.

28. Zhang G, Zhang J, Wang B, Zhu X, Wang Q, Qiu S. Analysis of clinical characteristics and laboratory findings of 95 cases of 2019 novel coronavirus pneumonia in Wuhan, China: a retrospective analysis. Respir Res 2020;21:74.

29. Chen G, Wu D, Guo W, Cao $Y$, Huang D, Wang H, Wang T, Zhang $X$, Chen $H$, Yu $H$, Zhang $X$, Zhang $M$, Wu S, Song J, Chen T, Han M, Li S, Luo X, Zhao J, Ning Q. Clinical and immunological features of severe and moderate coronavirus disease 2019. J Clin Invest 2020;130:2620-2629.

30. Ministry of Health - Republic of Turkey https://saglik.gov.tr/.

31. Remuzzi A, Remuzzi G. COVID-19 and Italy: what next? Lancet 2020;395:1225-1228.

32. Opal SM, Girard TD, Ely EW. The immunopathogenesis of sepsis in elderly patients. Clin Infect Dis 2005;41(Suppl 7):S504-S512.

33. Grubeck-Loebenstein B, Wick G. The aging of the immune system. Adv Immunol 2002;80:243-284.

34. Opal SM, Esmon CT. Bench-to-bedside review: functional relationships between coagulation and the innate immune response and their respective roles in the pathogenesis of sepsis. Crit Care 2003;7:23-38.

35. Cohen HJ, Harris T, Pieper CF. Coagulation and activation of inflammatory pathways in the development of functional decline and mortality in the elderly. Am J Med 2003;114:180-187.

36. Yamamoto K, Takeshita K, Kojima T, Takamatsu J, Saito H. Aging and plasminogen activator inhibitor-1 (PAl-1) regulation: implication in the pathogenesis of thrombotic disorders in the elderly. Cardiovasc Res 2005;66:276-285.

37. Guan WJ, Ni ZY, Hu Y, Liang WH, Ou CQ, He JX, Liu L, Shan H, Lei CL, Hui DSC, Du B, Li L, Zeng G, Yuen KY, Chen RC, Tang CL, Wang T, Chen PY, Xiang J, Li SY, Wang JL, Liang ZJ, Peng YX, Wei L, Liu Y, Hu YH, Peng P, Wang JM, Liu JY, Chen Z, Li G, Zheng ZJ, Qiu SQ, Luo J, Ye CJ, Zhu SY, Zhong NS; China Medical Treatment Expert Group for Covid-19. Clinical Characteristics of Coronavirus Disease 2019 in China. N Engl J Med 2020;382:1708-1720. 